\title{
ALMACENES COMERCIALES FRANCESES EN GUADALAJARA, MÉXICO (1850-1930)
}

\section{FRENCH COMMERCIAL DEPARTMENT STORES IN GUADALAJARA, MEXICO (1850-1930)}

\author{
Sergio Valerio Ulloa \\ Universidad de Guadalajara, Jalisco, México, valerio601223@yahoo.com.mx
}

\begin{abstract}
Resumen. Este artículo explica la forma en que un grupo de inmigrantes franceses llegó a la ciudad de Guadalajara durante la segunda mitad del siglo XIX y las primeras tres décadas del xx e instaló sus negocios comerciales, pasando de pequeñas tiendas de ropa a modernos almacenes organizados por departamentos. Dichos negocios también cambiaron las viejas casas coloniales donde inicialmente se ubicaban, en las calles céntricas de la ciudad, a bellos y lujosos edificios de tres y cuatro pisos. La hipótesis general sostenida en este trabajo es que estos inmigrantes galos llegaron a Guadalajara con muy poco capital o sin él, y a través del crédito y el capital social de sus redes familiares y empresariales se fueron abriendo paso en el mercado regional, al tiempo que reinvertían sus ganancias, incrementaban sus capitales, expandían sus empresas y diversificaban sus inversiones.
\end{abstract}

Palabras clave: franceses; barcelonnette; Guadalajara; migración; comerciantes; almacenes.

Abstract. This article explains the way in which a group of French immigrants arrived to the city of Guadalajara during the second half of the XIX century and the first three decades of the Xx century and installed their commercial businesses, evolving from small clothing stores to modern warehouses organized by departments. These stores also changed the old colonial houses, where they initially settled in the downtown streets of the city, for beautiful and luxurious three or four story buildings. The general hypothesis adopted by this work is that these Gallic immigrants arrived to Guadalajara with little to no capital, and through credit lines and the social capital of their family and company networks, they started making their way in the regional market; while reinvesting their earnings, they increased their capital shares, expanded their companies and diversified their investments.

Key words: French; Barcelonette; Guadalajara; migration; merchants; department stores.

Fecha de recepción: 26 de agosto de 2014. Fecha de aceptación: 3 de marzo de 2015.

Am. Lat. Hist. Econ., año 23, núm. 1, enero-abril, 2016, pp. 68-89 


\section{INTRODUCCIÓN}

$\mathrm{D}$ urante el siglo XIX el comercio experimentó un cambio muy importante. La revolución industrial hizo posible la producción masiva de mercancías a precios más asequibles, esto impulsó la modernización de los establecimientos comerciales y las formas de venta. Por tanto, la revolución industrial fue seguida por una revolución comercial, en la cual los comerciantes exitosos introdujeron nuevos métodos de venta para atraer más clientes, así como para interpretar sus necesidades y deseos, al mismo tiempo que presentaban las mercancías de una manera más atractiva a través de la publicidad en periódicos, revistas, carteles y aparadores (Luis, 2013, pp. 23-24; Toboso, 2002, p. 8).

A mediados de dicho siglo, París vio surgir los modernos almacenes comerciales. Situados en el centro de la ciudad y organizados en varias plantas y secciones, los grandes almacenes ofrecían una gran variedad de productos enfocados a satisfacer las necesidades y deseos de una creciente población ávida de consumo suntuario y de vestir a la moda. Algunos los veían como bellos palacios del comercio, pero otros los consideraban verdaderos monstruos que devoraban personas y vomitaban mercancías. Este proceso de modernización, competencia y desplazamiento de las pequeñas tiendas por los grandes almacenes comerciales fue narrado magistralmente por Emile Zola (1999). Para él significó el enfrentamiento entre dos concepciones del mundo: por un lado, la modernidad y el progreso; por otro, la tradición y el atraso. Siguiendo el modelo de los almacenes parisinos se instalaron en las principales ciudades del continente americano almacenes mercantiles que trataron de copiar el estilo y las formas comerciales y arquitectónicas de los almacenes franceses (Botero, 2007, pp. 93-114; Fernández, 2006; Zelaya, 2012). También en las principales ciudades de México se instalaron casas mercantiles que siguieron el ejemplo de los almacenes parisinos, y estuvieron en estrecha relación comercial con ellos, siendo los almacenes franceses los que proveían o financiaban con créditos y mercancías, estilos y modas a las casas comerciales situadas en las principales ciudades del país (Pérez, 2004, pp. 81-129).

Lo que se ofrecía en los grandes almacenes comerciales era la forma más elemental de la riqueza en el modo de producción capitalista: mercancías (Marx, 1982, t. I, p. 43); objetos que por un lado satisfacían las necesidades básicas de los seres humanos, como protegerse del frío y tapar la desnudez del cuerpo, y por otro las fantasías más extravagantes, exóticas, banales y superfluas provocadas por el deseo, el placer, el lujo, la seducción, la distinción y las derivadas de los extraños y fugaces giros y exigencias de la moda (Lipovetsky, 2010, pp. 76-171). 
Sin embargo, este trabajo no trata de las mercancías en términos abstractos, ni del sistema económico que las produce, mucho menos de su fetichismo, más bien analiza la forma concreta e histórica tal como se desarrolló en los almacenes comerciales franceses de Guadalajara, Jalisco, durante la segunda mitad del siglo XIX. Por lo tanto se inscribe dentro de los estudios de historia empresarial e historia de las empresas.

En los trabajos sobre historia empresarial han predominado hasta ahora tres enfoques teóricos (Collado, 1999, pp. 36-40): uno de ellos centra su atención sobre los cambios en la organización de las grandes empresas en el largo plazo, derivado de las aportaciones de Alfred Chandler (1996). Otro presta atención preferencial a la teoría del funcionamiento de las empresas y su relación con la economía a través de la dinámica de los mercados, lo cual se aplica dentro de la teoría de los costos de transacción, cuyo expositor más citado es Ronald Coase (1996). Un último enfoque centra su atención en el marco institucional de la economía, analizando en particular las condiciones establecidas por el marco jurídico e institucional en el funcionamiento económico de actores sociales y empresas, su exponente principal es Douglas North (1993). En este trabajo seguiré las propuestas de Chandler y de North con el objetivo de reconstruir la historia de los almacenes comerciales en Guadalajara.

Para ello he consultado distintas fuentes y archivos, tanto locales y nacionales como franceses, pero sobre todo he investigado en archivos notariales en Guadalajara. Dicha historia es muy similar a lo que pasó con distintos establecimientos comerciales nacionales y extranjeros en otras ciudades de México, Europa y Latinoamérica: pequeñas tiendas que se transformaron en grandes almacenes comerciales a partir de la reinversión y acumulación de capitales, dicho proceso fue acompañado por la formación de sociedades mercantiles y por un complejo proceso de diversificación de sus inversiones y actividades.

Mientras más se estudia a las empresas decimonónicas, más se encuentra a los empresarios asociados entre sí, formando grupos y compañías, como parte de redes familiares, étnicas, nacionales o internacionales; migrantes que se establecieron en países ajenos al suyo, pero que lograron insertarse en las sociedades locales e iniciar con pequeños negocios; posteriormente, de forma gradual y sostenida, llegaron a acumular una fortuna propia, reinvirtiéndola para incrementar su capital y transformar su pequeña empresa en un gran emporio. El grupo económico organizado como una red implica un conjunto de relaciones de alta confianza en el que cada miembro de la red, directa o indirectamente está vinculado con los demás en un grupo social. En la red los vínculos se establecen en términos de flujos de información, beneficios o bienes que se transmiten entre 
los sujetos que la conforman (Barbero, 2009, pp. 10-12; Bertrand, 1999, p. 119; Lizama y Valerio, 2006, p. 205).

Los grupos económicos han sido una constante en América Latina desde mediados del siglo XIX, pero con rasgos específicos sus actividades empresariales se realizan mediante asociaciones donde los vínculos preponderantes son de carácter familiar, étnico y sus orígenes han partido en términos mayoritarios de la actividad mercantil y de espacios regionales. Movilizan recursos familiares y también atraen capitales externos, maximizando utilidades en inversiones asociadas. Las actividades del grupo son coordinadas a través del entrecruzamiento de direcciones con un alto grado de lealtades y lazos familiares, así como reglas de comportamiento que solidifican la cohesión del grupo (Barbero, 2009, p. 13).

Estas características las podemos encontrar durante la segunda mitad del siglo XIX y la primera del XX para los grupos económicos nacionales y extranjeros en México, en ciudades como el Distrito Federal (Pérez, 2004, pp. 81-129), Puebla (Gamboa, 2001, pp. 159-178) y Guadalajara (Valerio, 2002); en España (Rodríguez, 2014; Toboso, 2002 y 2010) y en Argentina (Barbero, 2009, pp. 10-42); en Chile (Betancourt, 2012; Krebs, 2001); en Colombia (Botero, 2007, pp. 93-114; Safford, 2002, t. 1, pp. 375-406), y en Perú (Riviele, 2007, pp. 109-121).

La historia de los empresarios y sus empresas es un campo de estudio que ha alcanzado un importante adelanto en varios países industrializados y en algunos países latinoamericanos (Marichal, 1997, pp. 9-38). El estudio de los grandes almacenes comerciales franceses que aquí se presenta forma parte de esta historia.

\section{EL INICIO DE LAS CASAS COMERCIALES FRANCESAS EN GUADALAJARA DURANTE EL SIGLO XIX}

Los primeros franceses llegaron a Guadalajara a mediados del siglo XIX cuando esta ciudad contaba con aproximadamente 63000 habitantes. Comparados con los 170000 habitantes de la ciudad de México en esa misma época, resulta que Guadalajara tenía 2.7 veces menos pobladores que la capital del país y, a pesar de ello, constituía la segunda ciudad en importancia a nivel nacional. Al inicio del siglo Xx Guadalajara ya tenía 101208 habitantes, este crecimiento se debió a la continua migración de los pobladores de las comarcas aledañas a Guadalajara y de los estados vecinos a Jalisco (Becerra y Solís, 1994, pp. 29-51; Instituto Nacional de Estadística y Geografía, 1985, t. I, pp. 27-30).

Desde mediados del siglo XVIII, Guadalajara se había convertido en el centro urbano, mercantil, político y cultural más importante de una ex- 
tensa región en el occidente del país (véase mapa 1). La actividad agrícola y ganadera en esta región se llevaba a cabo, durante la época colonial y el siglo XIX, en torno a 380 haciendas, cerca de 3000 ranchos y poco más de 250 comunidades rurales, las cuales producían una gran variedad de artículos para el consumo de la población. Una parte de dicha producción se destinaba a satisfacer las necesidades de las mismas haciendas, ranchos y comunidades, y otra parte era enviada a los mercados local, regional y nacional. La ciudad de Guadalajara también era el centro de interconexión de las rutas del comercio a largas distancias, tanto hacia el centro y sur del país, como hacia el norte y noroeste del mismo. La importancia de Guadalajara como centro urbano y comercial se reafirmó con la llegada del ferrocarril en 1888, con lo que la capital jalisciense y la región del occidente se integraron a los mercados nacional e internacional (Valerio, 2003, pp. 24-35).

A partir de 1850 los inmigrantes franceses comenzaron a establecer tiendas o "cajones" de ropa situados en los portales del centro de Guadalajara. Eran modestos negocios que se organizaban principalmente como compañías en comandita, integradas por un número de socios que variaba de dos a cinco, entre los cuales había uno o dos socios capitalistas y los otros eran socios industriales. Los socios capitalistas regularmente radicaban en Europa, de donde enviaban las mercancías que se vendían en la tienda de Guadalajara, mientras que los socios industriales se ocupaban de la dirección y administración del negocio en dicha ciudad. Los inicios de estos establecimientos comerciales fueron con poco capital, pero al pasar los años el capital se incrementó considerablemente. La duración de la compañía era generalmente de tres a cinco años; concluido el plazo estipulado, se reestructuraba la sociedad y cambiaba la razón social de la empresa. Si no había cambios, entonces se decidía continuar con la misma compañía por otro periodo (Valerio, 2002, pp. 141-142).

Los socios entraban y salían frecuentemente de estas empresas, había un cambio generacional: los socios fundadores, al hacerse viejos y haber acumulado una fortuna considerable, se retiraban para ir a disfrutar sus últimos años a Francia, posiblemente regresaban a su pueblo natal, estos eran sustituidos por jóvenes recién llegados de los Bajos Alpes. Cuando alguno de los socios moría, se reestructuraba la empresa y se admitían nuevos integrantes en la compañía. Algunos miembros de la sociedad mercantil decidían abandonar la empresa y fundar otra con el capital acumulado durante varios años de permanencia en la negociación (Valerio, 2002, pp. 27-57).

Aunque las descripciones de época de varios viajeros franceses, que visitaron México durante el siglo XIX, se refieren particularmente a las tiendas ubicadas en la capital del país, estas nos pueden dar una aproxima- 


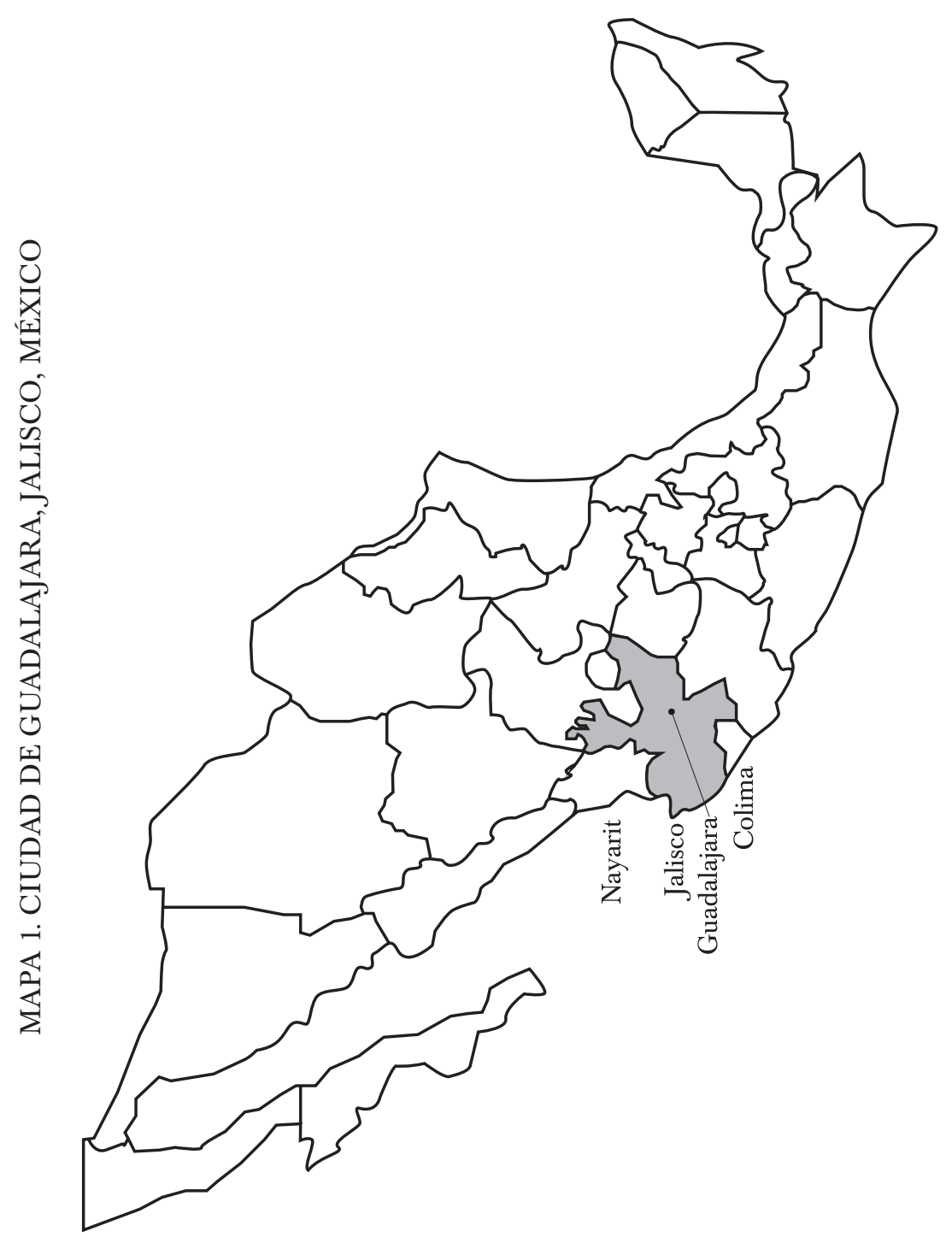

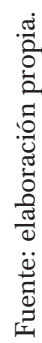


da idea de cómo funcionaban los almacenes comerciales en Guadalajara durante el siglo XIX.

En estas casas comerciales se trabajaba todo el año, con excepción de los días de fiesta, principalmente el 14 de julio, el 16 de septiembre y el 1 de enero. Las puertas del almacén se abrían de las siete de la mañana hasta las diez de la noche, a veces se prolongaba hasta la media noche, sobre todo cuando había "baratas", ventas especiales en las cuales se ofrecían bajos precios. El mostrador se colocaba a lo largo de la casa, a tres metros de las entradas, el cual separaba a los clientes de los vendedores. Estos se encontraban de pie detrás del mostrador. Desde las primeras horas de la mañana se ocupaban de exponer y acomodar las mercancías, estaban vestidos muy correctamente, la mayoría con traje, "el lápiz en la oreja, las tijeras en el bolsillo del chaleco, las manos apoyadas en los bordes del mostrador, esperando la llegada de los clientes". Todos bajo la vigilancia del jefe, que no perdía ninguno de sus movimientos (Chabrand, 1992, pp. 21-22).

Detrás de los empleados y frente a las puertas se encontraban los estantes y las gavetas llenas de cajones, ordenados de forma vertical, donde se guardaban las sederías y los artículos delicados. A diferencia de los grandes almacenes de Francia, donde cada empleado tenía su especialidad y donde el cliente pasaba de mano en mano según los artículos, en el caso de los almacenes mexicanos un solo empleado atendía al cliente y le vendía todas las mercancías de la casa. Una puerta al final del mostrador podía llevar al interior del establecimiento, y pasar a las salas del almacén llamadas trastienda. Del suelo al techo, las paredes estaban cubiertas de estantes para telas, en el centro se encontraban los mostradores, era la reserva y allí también se hacía la venta al mayoreo y al menudeo (Chabrand, 1992, p. 22).

Los almacenes de los barcelonnettes estaban ubicados en las calles céntricas de Guadalajara. Durante la mayor parte del siglo XIX ocuparon los edificios coloniales de una y dos plantas. Estas casonas se utilizaban en su totalidad, pues en la planta baja se ubicaba la tienda y la trastienda que se usaba como almacén. El segundo piso estaba destinado para las habitaciones de los dueños y empleados de confianza, ahí estaba la cocina y el comedor. Así sucedía con los almacenes Las Fábricas de Francia (Valerio, 2010) y La Ciudad de México en Guadalajara, en donde hasta se contrataba a una cocinera francesa para preparar la comida (Dejoie y Dejoie, 2009, p. 18; Cuzin de le Brun, 2008, pp. 11-37). Marvin Wheat (1994), un viajero estadunidense en 1857, nos dice lo siguiente: "Los pisos altos de los portales están en general ocupados -con escasas excepciones- por los arrendatarios de los locales de abajo, y se dividen en pequeños almacenes y tiendas de varios tipos en los que mercancías europeas, chinas y mexi- 
canas compiten entre sí para atraer compradores" (p. 135). Estos portales eran propiedad eclesiástica y se alquilaban por una modesta suma anual. Con las reformas liberales la Iglesia se vio obligada a vender a sus arrendatarios dichas fincas, con lo cual resultaron beneficiados varios de los comerciantes franceses, quienes se convirtieron en dueños de los locales donde tenían sus negocios (Wheat, 1994, p. 136).

Durante la segunda mitad del siglo XIX las tiendas de los franceses en Guadalajara no eran lujosas; al igual que en otras ciudades del país, poco a poco comenzaron a lucir su razón social escrita con esmero en fachadas y marquesinas. No existía el concepto de exhibir las mercancías en escaparates, por lo que los empleados tomaban estas de los anaqueles para colocarlas sobre el mostrador, aunque algunos comercios ya contaban con el concepto de atención personalizada al ofrecer sillas, bancos o cómodos taburetes para los clientes que esperaban, mientras otros clientes eran atendidos por jóvenes bien vestidos, serviciales y acomedidos, cuyo único objetivo era realizar su trabajo con eficiencia (Béraud-Suberville, 2008, pp. 247-273).

Con la estabilidad política del porfiriato, el crecimiento económico y el incremento de la población en las principales ciudades y regiones del país se incrementó el volumen de las ventas de estos establecimientos, lo cual provocó que los edificios coloniales fueran insuficientes para almacenar tantas mercancías y dar un buen funcionamiento a los negocios. A fines del siglo XIX y principios del XX las casas comerciales francesas en Guadalajara comenzaron a expandir sus negocios, en algunos casos comprando o rentando las propiedades aledañas, o bien cambiando su domicilio a lugares más propicios para construir y modernizar tanto el aspecto estético como el funcional del negocio. Algunos optaron por remozar el antiguo edificio colonial, otros prefirieron derrumbarlo totalmente y construir otro con estilo arquitectónico afrancesado. Así se pasó de la fachada austera a las fachadas de grandes escaparates iluminados, protegidos por marquesinas que invitaban a la compra. También se transformaron y ampliaron los espacios interiores, diseñando y formando unidades integrales, espaciosas e iluminadas, desapareciendo los espacios cerrados, oscuros y poco prácticos (Béraud-Suberville, 2008, p. 259).

En edificios nuevos, la planta baja era el espacio propicio para la venta al menudeo. Los entrepisos se destinaban a las ventas al mayoreo y a las dependencias administrativas, todos decorados con marcos y ventanas, $\mathrm{y}$ enmarcados con delicados detalles decorativos. El último piso estaba reservado para las habitaciones de los empleados de confianza, en su mayor parte barcelonnettes (Béraud-Suberville, 2008, p. 260). El edificio se remataba además con un toque francés de los acabados: áticos, balcones, techos inclinados cubiertos de laja, con mansardas, lucarnas y torretas. Para fines 
del siglo XIX y principios del XX, en Guadalajara se comenzaron a construir edificios afrancesados de tres o cuatro pisos para albergar los almacenes de Las Fábricas de Francia, El Nuevo Mundo y La Ciudad de México.

Los galos introdujeron a Guadalajara nuevas formas de venta copiadas de París, adoptaron el sistema de precios fijos, desterrando el regateo. También introdujeron la exhibición de las mercancías en vitrinas. Por lo cual había una tendencia creciente a eliminar el mostrador, de modo que se produjera la circulación del cliente por el almacén. Otro elemento innovador fue la recurrencia a la publicidad pagada y a los catálogos de mercancías para incrementar las ventas (Béraud-Suberville, 2008, p. 258). Finalmente, introdujeron el gusto por el buen vestir, el lujo y la moda, aspectos que fueron muy apreciados por las clases media y alta de la sociedad tapatía.

Estos cambios experimentados a fines del siglo XIX constituyeron la evolución de los antiguos cajones de ropa a las modernos almacenes departamentales en Guadalajara, los cuales también se distinguirían por su participación en la formación de las principales compañías industriales para la fabricación de textiles, empresas bancarias, y de bienes raíces en dicha ciudad. Las casas comerciales francesas comenzaron a vender mercancías que se producían en sus fábricas textiles, sin abandonar la venta de productos importados como lo venían haciendo anteriormente. Al mismo tiempo, crearon extensas redes para adquirir los artículos directamente de los fabricantes, tanto nacionales como extranjeros, dejando con esto de vender a comisión y convirtiéndose en propietarios de los productos que vendían (Gómez-Galvarriato, 2008, pp. 189-227). También formaron una amplia organización de mercadeo para vender a las tiendas rurales y a los vendedores al menudeo de otras ciudades del occidente y noroeste de México.

En los almacenes franceses de Guadalajara había una jerarquía social, en primer lugar estaban los socios capitalistas que podían o no residir en Guadalajara, luego los socios industriales o administradores, que dirigían la empresa, y en tercer lugar los dependientes y empleados. En los primeros niveles se encontraban los socios de la negociación, los representantes y los apoderados, eran los jefes que compartían la dirección, la venta al detalle y al mayoreo, las compras del almacén, la correspondencia, la caja, la contabilidad, entre otras actividades (Chabrand, 1992, p. 22). En este grupo de socios y gerentes observamos que los individuos provenían en su mayor parte de Francia, aunque no exclusivamente, pues había compañías en donde los galos se asociaban con mexicanos o con individuos de otra nacionalidad. Los que tenían nacionalidad francesa provenían en su mayoría de los Bajos Alpes. Por debajo de ellos estaban los dependientes, que provenían en su mayor parte de la región de Barcelonnette, aunque no de manera exclusiva (Valerio, 2008, pp. 359-380). 
Atendiendo las limitaciones de espacio para este artículo, sólo analizaré dos de los almacenes más importantes establecidos en Guadalajara para el periodo de 1850 a 1930: La Ciudad de Londres y La Ciudad de México. El caso de Las Fábricas de Francia lo traté ampliamente en otro lugar (Valerio, 2010).

\section{La Ciudad de LONDRes}

El primer almacén comercial que establecieron los franceses en Guadalajara fue La Ciudad de Londres, ubicado en el centro de la ciudad, en la esquina de las calles 16 de Septiembre y Juárez. La fundación de este establecimiento ocurrió entre 1851 y 1858, según distintas fuentes (Proal y Charpenel, 1998, p. 42; Les Temps de Jalisco, 22 de noviembre de 1907, p. 4). A fines esa década, Théophile Lèbre junto con los hermanos Clément y Auguste Gandoulf se asociaron para especular sobre la compraventa de casas en el centro de Guadalajara, aprovechando para ello las leyes de desamortización. Théophile Lèbre era de Forcalquier, ${ }^{1}$ mientras que Clément y Auguste Gandoulf eran de Jausiers, ambas poblaciones están situadas en los Bajos Alpes. ${ }^{2}$ Clément Gandoulf nació el 16 de abril de 1829 y murió en Jausier en junio de 1885, por su parte, Auguste Gandoulf nació el 3 de mayo de 1836 y murió también en su pueblo natal el 16 de enero de 1881. ${ }^{3}$ Clément Gandoulf solicitó un pasaporte para salir de Francia el 13 de septiembre de 1848, mientras que su hermano Auguste lo pidió el 5 de diciembre de $1854 .{ }^{4}$ En enero de 1858 compraron una tienda a Manuel Monsilla, situada en el primer cuartel de Guadalajara y valuada en 921 pesos, perteneciente al Colegio de los Agustinos. Dicha finca fue denunciada y rematada en función de las leyes de desamortización, y trasladada a favor de Théophile Lèbre; en esta transacción Clément Gandoulf apareció como fiador de Lèbre. ${ }^{5}$

La sociedad entre Lèbre y los Gandoulf también tuvo el objetivo de comerciar con ropa y lencería en una tienda instalada en el centro de la ciudad bajo la razón social Lèbre y Gandoulf, la tienda se llamó La Ciudad de Londres. Esta compañía apoyó la formación de otra que giró como

\footnotetext{
${ }^{1}$ Pasaporte de Théophile Lèbre con fecha de 1864. Archivo Histórico de Jalisco, G-8-1865, exp. 31 , f. 96 .

${ }^{2}$ Juan Riestra, protocolo, vol. xxxv, fs. 321-323. Archivo de Instrumentos Públicos de Jalisco (en adelante AIPJ).

${ }^{3}$ Tumba de la familia Gandoulf, cementerio de Jausiers, Francia.

${ }^{4}$ Sabença de la Valeia, lista de barcelonnettes quienes pidieron un pasaporte desde 1833 hasta 1868. Pasaportes hechos en la Prefectura de los Bajos Alpes.

${ }^{5}$ Francisco Riestra, protocolo, vol. I, fs. 1-2, 4 de enero de 1858. AIPJ.
} 
tienda de ropa, en la que operaron los hermanos Jacques y Émile Gandoulf, pero donde el socio capitalista era la compañía Lèbre y Gandoulf, con un capital de 10000 pesos en efectos de ropa. La razón social de esta nueva compañía fue Gandoulf Hermanos y Cía. y se registró el 22 de abril de $1861 .{ }^{6}$ En esta negociación Émile Gandoulf fue socio capitalista, con un capital de 2113 pesos proveniente de las utilidades que ganó como empleado de los señores Lèbre y Gandoulf, y al mismo tiempo también fue socio industrial, porque se encargó de la dirección y administración del negocio, al igual que su hermano Jacques. Como socios industriales, Jacques y Émile Gandoulf tomaban 20 pesos mensuales para su manutención y otros 20 pesos con cargo a sus utilidades. ${ }^{7}$

$\mathrm{Al}$ inicio de la década de 1870 Théophile Lèbre, Clément y Auguste Gandoulf continuaban con el comercio de ropa y lencería en la negociación Lèbre, Gandoulf y Cía., pero Clément se separó en 1876 y Auguste a fines de 1878. A ambos se les liquidaron las utilidades que les correspondieron que eran de $42.5 \%$ para Clément y 15\% para Auguste. La disolución de esta compañía se llevó a cabo el 11 de diciembre de 1879. Posteriormente se formó otra sociedad integrada esta vez por Émile Lèbre, Adolphe H. Barriere y Théophile Lèbre, la cual giró bajo la razón social de E. Lèbre Barriere y Compañía. Posiblemente Auguste Gandoulf falleció por esas fechas y Clément heredó los bienes de su hermano, por lo que trataron de poner fin a la compañía. ${ }^{8}$ Por su parte, Émile Lèbre nació en Forcalquier en 1852, mientras que Adolphe H. Barriere nació en México en 1847 , pero se consideraba de nacionalidad francesa. ${ }^{9}$

A partir de esta liquidación, Clément Gandoulf se quedó con las siete casas compradas en Guadalajara y los créditos a favor de la negociación Lèbre Gandoulf y Compañía, de tal manera que a Clément le correspondió un total de 12650 pesos. Una vez acordada la liquidación Clément dio en arrendamiento a los señores E. Lèbre Barriere y Cía. la tienda donde se hallaban el establecimiento comercial y la casa de altos que había sobre ella, por 120 pesos mensuales y por el término de tres años. ${ }^{10}$

El socio capitalista de la nueva compañía fue Théophile Lèbre, quien aportó 30000 pesos, mientras que Émile Lèbre y Adolphe Barriere eran socios gestores, introduciendo a la sociedad 2000 pesos cada uno. Esta sociedad giró por seis años y las utilidades se repartieron en tres partes iguales, mientras que cada socio pudo disponer de 100 pesos mensuales. Clément Gandoulf dejó a la nueva compañía un capital de 30000 pesos

\footnotetext{
${ }^{6}$ Juan Riestra, protocolo, vol. XVI, 22 de abril de 1861. AIPJ.

7 Juan Riestra, protocolo, vol. XVI, 22 de abril de 1861. AIPJ.

${ }^{8}$ Emeterio Robles Gil, protocolo, vol. 19, fs. 265-275, 11 de enero de 1883. AIPJ.

${ }^{9}$ Registro de Guadalajara, 1886-1891. Centro de Archivos Diplomáticos de Nantes.

${ }^{10}$ Registro de Guadalajara, 1886-1891. Centro de Archivos Diplomáticos de Nantes.
} 
que esta le pagaría en abonos mensuales de 5000 pesos por seis años con un rédito de $7 \%$ anual. ${ }^{11}$

La negociación E. Lèbre Barriere y Cía. continuó girando con los socios Émile Lèbre y Adolphe Barriere, hasta que el 14 de septiembre de 1896 se disolvió por la separación de Barriere, en esa fecha la compañía se reestructuró con la admisión de los nuevos socios Joseph Lèbre y Josephine Roy de Lèbre. ${ }^{12}$ Joseph era sobrino de Émile y originario de Forcalquier, nacido en 1868. Por su parte, Josephine era esposa de Émile y había nacido en Manosque en 1868. ${ }^{13}$ Al separarse Adolphe Barriere, la compañía le quedó debiendo la cantidad de 6000 pesos, los cuales la misma negociación se comprometió a pagarle. Además Adolphe era el representante de todos los derechos hereditarios de su madre, Olivia Barriere, quien fue acreedora de la compañía por la cantidad de 4526 pesos. Los socios de la misma se comprometieron a pagar a Adolphe por este concepto la suma de 10527 pesos, en moneda corriente de plata y en ocho mensualidades iguales, con el rédito de $10 \%$ anual. ${ }^{14}$

La mayor parte de la documentación notarial referente a la negociación E. Lèbre y Cía. trata de cobros a libranzas y letras de clientes que no pagaban o no podían pagar. Los trámites para hacer efectivos dichos documentos eran tortuosos y costosos, sin embargo, a falta de dinero efectivo se necesitaba el crédito con todas sus dificultades y costos, de otra manera no podían salir las mercancías de los almacenes, por lo que era necesario tener un temperamento muy resistente para estar entablando continuas demandas judiciales contra los morosos.

A pesar de ello, en mayo de 1888 La Ciudad de Londres seguía ofreciendo a sus clientes un magnífico surtido de efectos de ropa y sedería de lujo, medio lujo y corrientes traídos de Europa, Estados Unidos y la ciudad de México, según lo anunciaban en la prensa "a precios nunca vistos" en Guadalajara (Diario de Jalisco, 6 de mayo de 1888, p. 4). E. Lèbre y Cía. también participó en la constitución de la Compañía Industrial de Guadalajara en 1899, junto a otras compañías de origen francés. En esta compañía los socios de La Ciudad de Londres invirtieron 290000 pesos, correspondientes a $14.5 \%$ de las acciones. ${ }^{15}$

E. Lèbre y Cía. siguió funcionando en Guadalajara durante las dos primeras décadas del siglo Xx. En 1907 tenía como socios a Émile y Joseph Lèbre y a Gaston Garcin, y como dependientes a Alfred Lèbre, Etienne Honoré y Auguste Truttier (Les Temps de Jalisco, 22 de noviembre de 1907).

\footnotetext{
${ }^{11}$ Heraclio Garciadiego, protocolo, t. 13, 11 de diciembre de 1879. AIPJ.

12 Aurelio Hermosillo, protocolo, t. 4, 14 de septiembre de 1896. AIPJ.

${ }^{13}$ Registro de Guadalajara, 1891. Centro de Archivos Diplomáticos de Nantes.

${ }^{14}$ Aurelio Hermosillo, protocolo, t. 4, 14 de septiembre de 1896. AIPJ.

${ }_{15}$ Aurelio Hermosillo, protocolo, t. 4, 10 de julio de 1896. AIPJ.
} 
Posteriormente, el 16 de diciembre de 1915 se reformó la compañía con la participación de Auguste Truttier, Émile y Joseph Lèbre, con un capital de 150000 pesos. El término de esta compañía estaba estipulado para el 31 de diciembre de 1920, pero Auguste decidió separarse de la sociedad antes, obteniendo su liquidación el 6 de febrero de 1919, y quedando como socios Émile y Joseph Lèbre, quienes procedieron a hacer modificaciones a las cláusulas de la escritura constitutiva. ${ }^{16}$ Pero con motivo de la muerte de Émile, ocurrida el 14 de septiembre de 1919, se declaró disuelta la sociedad. A consecuencia de ello, la nueva compañía tuvo la razón social E. Lèbre y Cía. Sucesores, formada el 19 de febrero de 1920, siendo socios de esta Joseph Lèbre, Honorato Etienne y Auguste Truttier. ${ }^{17}$

Emile Lèbre y Josephine Roy radicaban en Manosque, Francia, sus hijos fueron Alfred (nacido en Guadalajara en 1888), Émilie (nacida en Manosque en 1890), Marie y Pierre Lèbre (nacidos en México). A la muerte de Émile Lèbre se disolvió la compañía y se practicó el balance de la liquidación correspondiente. El capital que le tocó a Émile les fue íntegramente pagado a los representantes de sus herederos: esposa e hijos. Mientras que su sobrino Joseph se quedó con los activos y pasivos de la negociación. ${ }^{18}$

En un balance practicado a la negociación E. Lèbre y Cía. en octubre de 1914, las transacciones dieron un total de 2131624 pesos. Lo más interesante del balance fueron las inversiones que tenía en otros negocios: acciones en La Fe por 1057 pesos; 290 acciones en la Compañía Industrial de Guadalajara por 203000 pesos; 295 acciones en La Parisiense por 28700 pesos; acciones en la Compañía Bancaria de París y México por 15000 pesos; acciones en La Ciudad de París por 40000 pesos; 206 acciones en el Banco de Jalisco por 20840 pesos, y acciones en la Compañía Petrolera del Pánuco y Támesi, por 150 pesos. ${ }^{19}$

\section{La Ciudad de MÉXico}

El almacén denominado La Ciudad de México fue fundado en 1880 por los socios Adrien Berlie y Eugène Cogordan. El edificio que ocupaba este almacén estaba situado en la esquina de 16 de Septiembre y Pedro Moreno. Adrien Berlie había sido socio anteriormente de Las Fábricas de Francia, de la cual se separó para formar una nueva compañía bajo la razón social Berlie y Cogordan, que giraba en Guadalajara en el ramo de lencería

\footnotetext{
${ }^{16}$ Teodoro Rojas, protocolo, vol. 13, fs. 151-162, 19 de febrero de 1920. AIPJ.

${ }^{17}$ Archivo Histórico de Jalisco, F-9-920, exp. 10567, 5 f, caja 361.

${ }^{18}$ Teodoro Rojas, protocolo, vol. 13, fs. 151-162, 19 de febrero de 1920. AIPJ.

${ }^{19}$ Manuel M. Tortolero, protocolo, vol. 36, fs. 1-11, 4 de diciembre de 1914. AIPJ.
} 
y sedería. Por su parte, Eugène Cogordan habitaba en Guadalajara desde 1878, también era comerciante, estaba soltero y poseía un capital de 6000 pesos hacia $1881 .{ }^{20}$ Cogordan nació en Jausiers en 1850, de tal manera que cuando llegó a Guadalajara era un joven de 18 años de edad. ${ }^{21}$

El 3 de septiembre de 1880, Berlie traspasó la tienda a Louis Gas y a Félix Cogordan, quienes se organizaron bajo la razón social de Gas y Cogordan, por un plazo de tres años, dividiéndose las utilidades por mitad, en tanto que cada socio pudo disponer de 50 pesos mensuales. ${ }^{22}$ Félix Cogordan murió el 18 de diciembre de 1891, por lo que fue preciso retirar su nombre de la negociación. Los socios que se quedaron con la compañía fueron los hermanos Louis y Antoine Gas y Élisée Reynaud, quienes decidieron admitir como nuevo socio a Edouard Gueymard con un capital de 1500 pesos. Los cuatro socios establecieron una nueva compañía bajo la razón social L. Gas y Compañía. En esta sociedad las ganancias se dividieron de la siguiente manera: 28\% fue para Louis Gas, 26\% para Elisée Reynaud, otro 26\% para Antoine Gas y 15\% para Edouard Gueymard, el $5 \%$ restante fue para gratificar al dependiente que a juicio de la mayoría se hubiera conducido mejor en el año. ${ }^{23}$

Los socios provenían del valle de Barcelonnette, los hermanos Gas y Edouard Gueymar nacieron en Jausiers y Elisée Reynaud era de LaCondamine. Louis Gas era el mayor de edad, pues había nacido en 1855, y hacia 1891 ya contaba con 36 años. Su hermano Antoine era menor que él, nació en 1863, y tenía 28 años al entrar a la compañía. Por su parte, Reynaud nació en 1858, de tal manera que cuando se formó la sociedad en 1891 tenía 33 años. En tanto que Gueymard, que nació en 1863, tenía 28 años al momento de ingresar a la negociación. ${ }^{24}$

El 23 de febrero de 1897 se reestructuró la sociedad de la cual formaron parte Louis y Antoine Gas, Eugène Cuzin y Benjamin Teissier. Los nuevos socios también provenían de Jausiers, es muy posible que Eugène Cuzin fuera primo de los hermanos Gas, y que a la vez fuera pariente de Benjamín Teissier. Incluso, Cuzin fue contratado desde Jausiers por los hermanos Gas en 1890, para que viniera a Guadalajara a trabajar como dependiente de La Ciudad de México. Siete años más tarde, Cuzin pudo ascender de empleado a socio de la compañía, siguiendo el camino de muchos jóvenes barcelonnettes que llegaban a México sin ningún capital y trabajaban como dependientes en los almacenes comerciales de sus paisanos.

\footnotetext{
${ }^{20}$ Archivo Histórico de Jalisco, G-10-881, JAL/3731.

${ }^{21}$ Registro de Guadalajara, 1891. Centro de Archivos Diplomáticos de Nantes.

${ }^{22}$ Emeterio Robles Gil, protocolo, t. 19, 6 de septiembre de 1882. AIPJ.

${ }^{23}$ Emeterio Robles Gil, protocolo, t. 36, 16 de diciembre de 1893. AIPJ.

${ }^{24}$ Registros de Guadalajara, 1886-1891. Centro de Archivos Diplomáticos de Nantes.
} 
En 1887 la negociación L. Gas y Compañía estuvo conformada de la siguiente manera: Louis Gas introdujo 15000 pesos y Antoine Gas aportó otros 10 000; de esta manera los hermanos Gas seguían siendo los principales socios capitalistas de la empresa. Por su parte, Eugène Cuzin y Henri Teissier introdujeron 2500 cada uno, para sumar un total de 30000 pesos como capital social de la compañía. Además del capital que introdujeron Cuzin y Teissier, se comprometieron a desempeñarse como socios industriales, renunciando a aceptar comisiones, a formar parte de otras sociedades o a emprender negocios por su cuenta. ${ }^{25}$

Louis Gas residía habitualmente en Francia y tenía completa libertad para permanecer en Guadalajara el tiempo que él estimara conveniente, además podía residir en cualquier parte del mundo, siendo enteramente voluntario para él ayudar a los otros socios en la administración y gerencia de la sociedad, desde cualquier parte donde él estuviera. ${ }^{26}$

El término de la sociedad fue el 31 de julio de 1902 y cada uno de los socios pudo disponer hasta de 1200 pesos anuales en calidad de sueldo y con cargo a gastos generales de la negociación. Además del sueldo, Louis y Antoine Gas podían disponer anualmente de 12000 pesos cada uno, si se encontraban en México, y hasta de 50000 francos anuales si residían en Europa, debiendo cargarse a sus cuentas particulares. A cada uno de los socios se le abonó $6 \%$ de interés anual, sobre los capitales que representaban respectivamente. Las ganancias de la sociedad se repartieron de la siguiente manera: Louis y Antoine Gas recibían 30\% cada uno, mientras que el $40 \%$ restante se lo repartían por partes iguales entre Eugène Cuzin y Benjamin Feissier. ${ }^{27}$

Todos los negocios de importancia debían ser acordados por la mayoría de los socios que se encontraban en Guadalajara, pero en caso de desacuerdo prevalecía la opinión de Louis Gas, como principal socio capitalista. Cuando no estaba Louis, se sujetaban a la opinión de su hermano Antoine, y en ausencia de este último, la opinión que prevalecía era la de Eugène Cuzin. La finca donde estaba la tienda La Ciudad de México era arrendada a Francisco Martínez Gallardo por 500 pesos mensuales. ${ }^{28}$

La sociedad L. Gas y Compañía participó, durante la década de 18901900, como socio en la fundación de la Compañía Industrial de Jalisco, en esta invirtió un capital de 62500 pesos; luego participó en la formación de la Compañía Industrial de Guadalajara con un capital de 600000 pesos, y casi al mismo tiempo, participaba en la constitución del Banco de

\footnotetext{
${ }^{25}$ Aurelio G. Hermosillo, protocolo, t. 5, 23 de febrero de 1897. AIPJ.

${ }^{26}$ Aurelio G. Hermosillo, protocolo, t. 5, 23 de febrero de 1897. AIPJ.

${ }^{27}$ Aurelio G. Hermosillo, protocolo, t. 5, 23 de febrero de 1897. AIPJ.

${ }^{28}$ Aurelio G. Hermosillo, protocolo, t. 5, 23 de febrero de 1897. AIPJ.
} 
Jalisco, con una inversión de 50000 pesos, junto con otros capitales galos, españoles y mexicanos (Valerio, 2002, pp. 116-134). Además especuló en la compraventa de terrenos y casas en Guadalajara; por ejemplo, junto con los señores Fernández del Valle, Fortoul y Chapuy y Ernest Fuchs fueron dueños del terreno donde se construyó la colonia Francesa. También se asoció con la casa Brun y Cía. y con el Banco de Jalisco para formar la Compañía de Fomento y Bienes Raíces de Guadalajara, en junio de 1910; esta compañía también incluía como socios a los señores Aurelio González Hermosillo, Abraham Gallardo y José Pacheco, inversionistas tapatíos. ${ }^{29}$

Además de lo anterior, los miembros de la compañía tenían excelentes relaciones con el gobierno del estado de Jalisco y con las autoridades francesas. Al iniciar el año de 1904, Antoine Gas fue nombrado agente consular en la ciudad de Guadalajara por parte del gobierno francés. En ese momento, las autoridades de Jalisco opinaron que Gas era "una persona de reconocida honorabilidad y de muy buenas cualidades personales". También informaron que Antoine y Louis Gas poseían varias fincas urbanas por un valor catastral de 36825 pesos. Afirmaban las autoridades jaliscienses que Antoine Gas tenía establecida en Guadalajara la casa comercial La Ciudad de México y que sus socios y esposa eran de nacionalidad francesa. Aclaraba el gobierno de Jalisco que Gas no había hecho reclamaciones en contra de México y que tampoco había participado en cuestiones políticas del país ni había ejercido ningún cargo público, por lo que las autoridades locales no tenían quejas en su contra. Dadas estas referencias, la Secretaría de Relaciones Exteriores de México autorizó a Antoine Gas para que ejerciera las funciones de agente consular en Guadalajara. ${ }^{30}$

Antoine Gas estuvo casado con Marie Caire, nacida en 1879; Gas murió en Barcelonnette en enero de 1947, a los 84 años de edad. Su esposa también murió en Barcelonnette en julio de 1955, a los 75 años. ${ }^{31}$

En 1907 los socios de la negociación L. Gas y Cía. eran Louis y Antoine Gas, Eugène Cuzin y Henri Teissier. Mientras que sus apoderados fueron Edouard Caire y Henri J. Teissier (Les Temps de Jalisco, 22 de noviembre de 1907). Eugène Cuzin trajo a sus sobrinos desde Jausiers; entre estos se contaban Henri, Jean, Eugene y Berthe Teissier y Edouard Caire. Jean Cuzin era su hermano, mientras que Ernest y Leon Caire, así como Calixte Teissier, posiblemente fueron sobrinos de Eugène Cuzin, con lo cual se evidencian los vínculos familiares y de paisanaje que predominaban entre los socios, dependientes y trabajadores de estos almacenes.

\footnotetext{
${ }^{29}$ Homobono Díaz, protocolo, 15 de junio de 1910. AIPJ.

${ }^{30}$ Carta del secretario de Gobierno del Estado de Jalisco al secretario de Relaciones Exteriores de México. Archivo Histórico de Jalisco, G-8-94, GUA/3724.

31 Tumba de la familia Gas, cementerio de Barcelonnette, Francia.
} 
Para atender sus negocios en la ciudad de México, la firma L. Gas y Cía. nombró como su representante a la compañía J. B. Ebrad y Cía. el 10 de diciembre de $1907^{32}$ De tal manera que sus empresas no se limitaban a la ciudad de Guadalajara; en la ciudad de México también tenían una tienda llamada París Londres.

Después de varias reorganizaciones en la década de 1910, el 31 de agosto de 1918 L. Gas y Compañía Sucesores contaba con un capital social de 500000 pesos. El capital introducido y las ganancias se distribuyeron de la manera siguiente: Louis Gas introdujo un capital de 150000 pesos, correspondiéndole 6\% de las utilidades; Antoine Gas participó con 250000 pesos con 10\% de las utilidades; Eugène Cuzin aportó 60000 pesos y obtuvo 23\% de las utilidades; mientras que Henry Teissier invirtió 40000 pesos con $23 \%$ de las utilidades. ${ }^{33}$

Esta compañía poseía los almacenes comerciales La Ciudad de México, en Guadalajara, París Londres, en la ciudad de México, la fábrica de camisas que tenía el nombre de American Clothing, y los demás bienes y valores que constaban en sus inventarios. En esta compañía cada uno de los socios pudo disponer de un sueldo de 500 pesos mensuales para sus gastos personales. ${ }^{34}$

La Ciudad de México dio el descanso dominical a sus empleados a partir de mayo de 1909 (El Regional, 19 de mayo de 1909, p. 2). Durante los años de 1914 y 1915 este almacén enfrentó una serie de problemas relacionados con la actividad de los ejércitos revolucionarios que tomaron la ciudad de Guadalajara, los cuales están relatados por Eugène Cuzin en su Diario (2008).

Son pocas cosas las que aportan los documentos encontrados en la década de 1910-1920 sobre la negociación L. Gas y Cía., si acaso lo más interesante es la compraventa de terrenos de la colonia Reforma, de la que fue propietaria. Durante 1915 se hicieron muchas escrituras por venta de lotes, con decir que hasta los mismos generales constitucionalistas Manuel M. Diéguez y Manuel Aguirre Berlanga compraron terrenos en la colonia Reforma, que fue una de las modernas, higiénicas y lujosas colonias al poniente de Guadalajara. ${ }^{35}$ También resulta interesante que L. Gas y Cía. realizara transacciones comerciales con los almacenes de calzado y equipo del ejército convencionista en abril de $1915 .^{36}$

${ }^{32}$ Alfonso Mancilla, protocolo, t. 7, 10 de diciembre de 1907. AIPJ.

${ }^{33}$ Manuel F. Chávez, protocolo, 31 de agosto de 1918. AIPJ.

${ }^{34}$ Manuel F. Chávez, protocolo, 31 de agosto de 1918. AIPJ.

${ }^{35}$ Manuel M. Tortolero, documentos, vols. 26, 38, 39. Con fechas de 31 de julio, 4, 6, 16, 25 y 26 de agosto de 1915. AIPJ.

${ }^{36}$ Manuel M. Tortolero, documentos, vol. 26, fs. 735-738, 6 de abril y 30 de agosto de 1915. AIPJ. 


\section{CONCLUSiOnes}

Los franceses que llegaron a Guadalajara durante el siglo XIX tuvieron en el comercio su principal actividad económica. Provenían en su mayoría del departamento de los Bajos Alpes. Instalaron sus negocios en las calles céntricas de la ciudad y, poco a poco, se consolidaron, reinvirtiendo sus ganancias en la misma negociación comercial o en otras, buscando diversificar sus actividades, obtener más ganancias y reducir los riesgos de una posible quiebra. Sus negocios se organizaron como sociedades en comandita, integradas principalmente con franceses provenientes de los Bajos Alpes. Formaron grupos y redes sociales y económicas, también se asociaron con mexicanos y con otros empresarios de otras nacionalidades.

Los primeros franceses que habían consolidado sus negocios mandaban traer a sus parientes y amigos de sus pueblos natales realizando una migración en cadena, los vínculos familiares y de paisanaje le dieron una fuerte cohesión al grupo y a las empresas, pues a través de la confianza y la estrecha colaboración entre parientes y amigos se eliminaban los riesgos y se reducían en gran medida los conflictos entre los miembros de la empresa, se posibilitaba el crédito y la administración de los negocios.

La movilidad al interior de los negocios permitió el cambio generacional, los socios viejos fueron sustituidos por inmigrantes jóvenes dispuestos a trabajar duramente para cumplir su sueño de hacer fortuna en México. Con un considerable capital acumulado, los bajoalpinos enriquecidos volvían a su patria a disfrutar su vejez al lado de sus familiares cercanos.

Por otra parte, algunos de los negocios de los franceses en Guadalajara evolucionaron de cajones de ropa a modernos almacenes comerciales y diversificaron sus actividades invirtiendo en la industria textil, la minería, la banca y la especulación inmobiliaria. En el transcurso del siglo XIX, las empresas galas se hacían más grandes y complejas, con capitales mayores y una estructura administrativa más adecuada y profesional, finalmente organizaron sus negocios como sociedades anónimas.

Las compañías comerciales francesas L. Gas y Cía. y Fortoul Chapuy y Cía. participaron, junto con otras compañías mexicanas y españolas, en la formación de la Compañía Industrial de Jalisco el 10 de diciembre de 1889. El objetivo de esta empresa, con 1000000 de pesos de capital social, fue la explotación de las fábricas: Atemajac, La Experiencia, Río Blanco y El Batán. Pero dicha compañía se disolvió en abril de $1891{ }^{37}$

El 2 de diciembre de 1899 las compañías comerciales francesas Fortoul Chapuy y Cía., L. Gas y Cía., E. Lebre y Cía., Bellón Agorreca y Cía.

${ }^{37}$ Heraclio Garciadiego, protocolo, t. 49, 10 de diciembre de 1889, y t. 51, 18 de abril de 1891. AIPJ. 
CUADRO 1. COMPAÑÍA INDUSTRIAL DE GUADALAJARA, 1899

\begin{tabular}{llccc}
\hline Socios & \multicolumn{1}{c}{ Almacén } & $\begin{array}{c}\text { Capital } \\
\text { (pesos) }\end{array}$ & Acciones & Porcentaje \\
Fortoul Chapuy y Cía. & Las Fábricas de Francia & 600000 & 6000 & 30 \\
L. Gas y Cía. & La Ciudad de México & 600000 & 6000 & 30 \\
E. Lèbre y Cía. & La Ciudad de Londres & 290000 & 2900 & 14.5 \\
Bellon Agorreca y Cía. & La Ciudad de París & 290000 & 2900 & 14.5 \\
Laurens Brun y Cía. & El Nuevo Mundo & 220000 & 2200 & 11 \\
Total & & 2000000 & 20000 & 100 \\
\hline
\end{tabular}

Fuente: Manuel Tortolero, protocolo, t. 15, 2 de diciembre de 1899. Archivo de Instrumentos Públicos de Jalisco.

y Laurens Brun y Cía. constituyeron la Compañía Industrial de Guadalajara. El objetivo de esta sociedad fue explotar las fábricas de hilados, tejidos y estampados de Atemajac y La Experiencia, más el Molino del Salvador, el Rancho Nuevo y los Baños de los Colomitos. El capital social de esta compañía fue de 2000000 de pesos, distribuido según se muestra en el cuadro $1 .^{38}$ Las compañías que constituyeron esta sociedad tomaban productos de las fábricas mencionadas con descuento, de tal manera que sus almacenes comerciales respectivos se surtieron continuamente de estas fábricas, logrando integrar la producción y el comercio de dichos géneros.

Entre 1890 y 1910 los empresarios franceses no sólo invirtieron en la Compañía Industrial de Guadalajara, también participaron en la formación de la Compañía Industrial Manufacturera, que tenía bajo su propiedad las fábricas textiles de El Salto, en Jalisco, y San Antonio, La Purísima y Hércules en Querétaro. Sus inversiones se extendieron al Banco de Jalisco, ${ }^{39}$ también participaron en la fábrica de jabones La Parisiense, invirtieron en el mercado inmobiliario de Guadalajara a través de la Compañía Jalisciense de Construcciones y en la Compañía de Bienes Raíces de Guadalajara, promotoras de las colonias modernas e higienistas denominadas colonias Francesa, Americana y Reforma (Valerio, 2010, p. 43). De esta manera, los capitales franceses en Guadalajara tuvieron una amplia diversificación abarcando el comercio, la industria, la banca y la promoción inmobiliaria.

\footnotetext{
${ }^{38}$ Manuel Tortolero, protocolo, t. 15, 2 de diciembre de 1899. AIPJ.

${ }^{39}$ José López Portillo y Rojas, protocolo, t. 2, 21 de febrero de 1898. AIPJ.
} 


\section{LISTA DE REFERENCIAS}

Barbero, M. I. (2009). Estrategias de empresarios italianos en Argentina. El Grupo Devoto. Anuario del Centro de Estudios Económicos de la Empresa y el Desarrollo, 1(1), 10-42.

Becerra, C. G. y Solís, A. (1994). La multiplicación de los tapatíos, 1821-1921. Zapopan: El Colegio de Jalisco.

Béraud-Suberville, G. (2008). Centinelas del pasado: del cajón de ropa a las tiendasancla. En L. GamboA (coord.), Los barcelonnettes en México. Miradas regionales, siglos XIX-XX (pp. 247-273). Puebla: Benemérita Universidad Autónoma de Puebla.

Bertrand, M. (abril-junio, 1999). De la familia a la red de sociabilidad. Revista Mexicana de Sociología, 61(2), 107-135.

Betancourt, F. (2012). Los comerciantes españoles y el proceso de independencia en Chile. Estrategias y desventuras en una época de cambios. Tiempo Histórico, 4, 121-138.

Botero, M. M. (junio, 2007). Casas comerciales y circuitos mercantiles Antioquia: 1842-1880. Revista Sociedad y Economía, 12, 93-114. Recuperado de http://www. redalyc.org/articulo.oa?id=99616724006

Chabrand, É. (1992). Les barcelonnettes au Mexique. Barcelonette: Sabença de la Valeia.

Chandler, A. (1996). Escala y diversificación. La dinámica del capitalismo industrial. Zaragoza: Prensas Universitarias de Zaragoza.

Coase, R. H. (1996). La naturaleza de la empresa. En O. Williamson y S. Oliver y Winter (comps.), La naturaleza de la empresa. Origen, evolución y desarrollo. México: Fondo de Cultura Económica.

Collado, M. Del C. (1999). Historia empresarial mexicana de 1850 a 1930. Revista de Economía Informa, 277, 35-40.

Cuzin de le Brun, L. (2008). Prefacio. En E. Cuzin, Diario de un francés en México durante la revolución, del 16 de noviembre de 1914 al 9 de julio de 1915 (pp. 11-37). México: Consejo Nacional para la Cultura y las Artes/Fondo Nacional para la Cultura y las Artes.

Cuzin, E. (2008). Diario de un francés en México durante la revolución, del 16 de noviembre de 1914 al 9 de julio de 1915. México: Consejo Nacional para la Cultura y las Artes/ Fondo Nacional para la Cultura y las Artes.

Dejoie, C. y Dejoie, C. (primavera, 2009). Le trésor de Fréderic Faideau déposé à la Sapiniére, Toute la Vallée. La vie en Ubaye, 42, 18.

FERnÁNDEZ, E. (2006). La migración francesa en Chile, 1875-1914: entre integración social y mantenimiento de la especificidad. Amérique Latine. Histoire E̊ Mémoire, 12. Recuperado de http://alhim.revues.org/1252\#tocfrom1n1

GAmbOA, L. (2001). Los comercios de los barcelonnettes y la cultura del consumo entre las élites urbanas: Puebla, 1862-1928. En J. PÉrez y CH. Cramausell (coords.). México Francia: memoria de una sensibilidad común, siglos XIX-XX (vol. II, pp. 159-178). Puebla: Benemérita Universidad Autónoma de Puebla/El Colegio de Michoacán. 
Gómez-Galvarriato, A. (2008). Los barcelonnettes y la modernización de la comercialización y de la producción de textiles en el porfiriato. En L. GAmbOA, (coord.). Los barcelonnettes en México. Miradas regionales, siglos XIX y XX. (pp. 189-227). Puebla: Benemérita Universidad Autónoma de Puebla.

Instituto NACIONAL de EstadísticA y GEOGRAFÍA [INEGI] (1985). Estadísticas históricas de México. 2 vols. México: InEgi/Instituto Nacional de Antropología e Historia

Krebs, A., TAPIA U. y Schmid P. (2001). Los alemanes y la comunidad chileno-alemana en la historia de Chile. Santiago de Chile: Liga Chileno-Alemana.

Lipovetsky, G. (2010). El imperio de lo efímero. La moda y su destino en las sociedades modernas. Barcelona: Anagrama.

Lizama, G. y VAlerio, S. (enero-abril, 2006). Redes empresariales en la región de Guadalajara durante el porfiriato. Secuencia. Revista de Historia y Ciencias Sociales, 64, 205-230.

Luis, S. (2013). Grandes almacenes comerciales y políticas de género de la empresa: El caso concreto de El Corte Inglés (Tesis inédita de maestría). Universidad de Salamanca, España. Recuperado de http://gredos.usal.es/jspui/bitstream/10366/122941/1/ TFM_LuisSanchez_Grandes.pdf

MARICHAL, C. (1997). Avances recientes en la historia de las grandes empresas y su importancia para la historia económica de México. En C. MARICHAL y M. CerutTi (comps.), Historia de las grandes empresas en México, 1850-1930. México: Fondo de Cultura Económica.

Martínez, F. (1991). Los tapatíos, un modo de vivir. Guadalajara: Ayuntamiento de Guadalajara.

MarX, K. (1982). El Capital. México: Siglo XXI Editores.

North, D. (1993). Instituciones, cambio institucional y desempeño económico. México: Fondo de Cultura Económica.

PÉrez, J. (2004). "Inversiones francesas en la modernidad porfirista: mecanismos y actores". En J. PÉRez y CH. CRAmussel (coords.), México-Francia: memoria de una sensibilidad común. Siglos XIX-XX (vol. II, pp. 81-129). México y Puebla: Benemérita Universidad Autónoma de Puebla/El Colegio de Michoacán/Centro de Estudios Mexicanos y Centroamericanos.

Proal, M. y Charpenel, P. M. (1998). Los barcelonnettes en México. México: Clío.

Riviale, P. (2007). Los franceses en el Perú del siglo XIX: retrato de una emigración discreta. Bulletin de l'Institut Français d'Études Andines, 36(1), 109-121. Recuperado de http://www.ifeanet.org/publicaciones/boletines/36\%281\%29/109.pdf

Rodríguez-VigiL, J. M. (2014). “Tradición asturiana de distinción”: una aproximación al estudio de los grandes almacenes Botas. Revista Anual de Historia del Arte, 20, pp. 109-124.

SAFFord, F. (2002). Francisco Vargas, un comerciante de corte inglés. En C. DÁvilA (comp.), Empresas y empresarios en Colombia, siglos XIX y XX (pp. 375-406). Bogotá: Norma/Universidad de los Andes/Comisión Económica para América Latina y el Caribe. 
Toвoso, P. (2002). Grandes almacenes y almacenes populares en España. Una visión histórica (Documento de trabajo inédito). Universidad Autónoma de Madrid, España. Recuperado de ftp://ftp.fundacionsepi.es/phe/hdt2002_2.pdf

Toboso, P. (2010). Los orígenes cubanos de El Corte Inglés y de Galarías Preciado: los dos grandes almacenes del comercio en España. $9^{\circ}$ Encuentro Internacional de Associação Nacional de Pesquisadores e Professores de História das Américas, Goiás: Universidade Federal de Goiás. Recuperado de http://anphlac.fflch.usp.br/sites/anphlac. fflch.usp.br/files/Sanchez\%20PT.pdf

VALERIO, S. (2002). Empresarios extranjeros en Guadalajara durante el porfiriato. Guadalajara: Universidad de Guadalajara.

VAlERIO, S. (2003). Historia rural jalisciense. Economía agrícola e innovación tecnológica durante el siglo XIX. Guadalajara: Universidad de Guadalajara.

VAlERIO, S. (2008). Barcelonnettes en Guadalajara durante el siglo XIX: inmigración y actividades económicas. Puebla: Benemérita Universidad Autónoma de Puebla.

VAlerio, S. (2010). Las Fábricas de Francia: historia de un almacén comercial en Guadalajara. Guadalajara: Universidad de Guadalajara.

Wheat, M. (1994). Cartas de viaje por el Occidente de México. Zapopan: El Colegio de Jalisco.

ZelayA, R. (26 de febrero, 2012). El cambio del siglo XIX al siglo XX: Comercio en Tegucigalpa y Comayagüela. La Tribuna. Recuperado de http://www.latribuna. hn/2012/02/26/el-cambio-de-siglo-xix-a-siglo-xx-comercio-en-tegucigalpa-ycomayaguela/

ZolÁ, E. (1999). El paraíso de las damas. Barcelona: Alba Editorial.

\section{OTRAS FUENTES}

\section{Archivos}

Archivo de Instrumentos Públicos de Jalisco, Guadalajara, México.

Archivo Histórico de Jalisco, Guadalajara, México.

Cementerios de Barcelonnette y Jausiers, Francia.

Centre des Archives Diplomatiques de Nantes, Nantes, Francia.

\section{Hemerografia}

Diario de Jalisco; El Regional, y Les Temps de Jalisco. En Fondos Especiales. Biblioteca Pública del Estado de Jalisco [BPEJ], Guadalajara, México. 